\title{
Planeamento e Governança Territorial Uma Reflexão Sociológica a Partir do Terreno ${ }^{l}$
}

Walter Rodrigues*

\begin{abstract}
$\mathrm{R}$ tâncias de governança territorial, o artigo dá conta de uma reflexão, a esse propósito, equacionada em dois planos. Por um lado, no plano da postura da sociologia e do sociólogo face a um tal terreno de trabalho e a uma específica modalidade de exercício das suas competências profissionais e científicas. Por outro lado, no plano do concreto da realidade do país, com o seu nível de desenvolvimento próprio e a sua especificidade, em termos económicos, políticos, sociais e culturais, confrontado, sobretudo na última década, com a pressão para acelerar processos de desenvolvimento a todos aqueles níveis e, simultaneamente, fazer face às novas exigências da actual fase de transição. $\mathrm{O}$ artigo reporta a complexidade, no contexto português, do papel da sociologia no trabalho em "planeamento estratégico participado" e da implementação de "novas formas de regulação social a nível local" e conclui pela necessidade de concepção da ideia de governança "como processo", enunciando, a este propósito, alguns pontos para posterior aprofundamento da reflexão.
\end{abstract}

Palavras-chave: planeamento estratégico; governança; regulação social; parcerias; globalização; transição; metodologias de planeamento; desenvolvimento local.

\section{Prólogo}

Os efeitos conjugados, e contraditórios, de múltiplos factores de mudança que desenham a fase de transição actual concorrem para novas exigências ao trabalho da sociologia, ao nível territorial, que se constituem como novas oportunidades, mas também novos riscos, que exigem, igualmente, um amplo debate sobre o papel que nesse contexto podem desempenhar as ciências sociais em geral e a sociologia e os sociólogos em particular.

Referimo-nos aos efeitos conjugados dos processos de globalização, da transição de "regime económico", da crescente crise financeira do Estado, da crescente incapacidade dos governos nacionais para o desempenho da sua função de regulação social, que vêm motivando a necessida- de de adopção de princípios de governança de base territorial e âmbito local, ou regional.

Não se trata de uma "crise de legitimidade" da governação por parte tanto dos governos nacionais quanto locais. Muito menos de uma "crise de legitimidade" do modelo representativo da democracia, em que aquela governação se exerce. Trata-se, isso sim, da consciência crescente de que no contexto actual, motivado pela complexa conjugação dos factores que acima enunciámos, tudo parece indicar a necessidade de reinventar modelos de regulação flexíveis, inovadores e imaginativos, ao nível dos territórios locais ou regionais, para fazer face aos efeitos contraditórios, complexos e sempre singulares em cada contexto territorial, daqueles factores da transição actual.

\footnotetext{
* Sociólogo. Docente do Departamento de Sociologia do ISCTE e Investigador do CET. Contacto: walter.rodrigues@iscte.pt

' A experiência de trabalho que permitiu a reflexão que este texto apresenta beneficiou de um trabalho de equipa com as colegas Margarida Perestrelo, Iulce Moura e Teresa Amor. Além dos diversos projectos em que trabalhámos em equipa, o presente artigo é ainda devedor do intercâmbio com dezenas de actores no terreno, no âmbito daqueles projectos e também de diversas acções de formação em Planeamento e Desenvolvimento Local. Finalmente, importa registar que este artigo é também tributário do trabalho que tem sido desenvolvido em matéria de metodologias de planeamento e pesquisa de terreno pela colega Prof. Isabel Guerra. A todos o autor expressa publicamente a sua gratidão.
} 
A adopção de princípios de governança, sobretudo ao nível local, tem vindo a motivar a requisição da intervenção das competências da sociologia num terreno e numa perspectiva que colocam um conjunto de novas questões à disciplina, do ponto de vista metodológico, epistemológico e até deontológico. Não se trata da discussão em torno do papel da sociologia na produção de estudos para o planeamento, decisão política ou intervenção técnica, em determinada área de acção, mas sim do papel que a sociologia e o sociólogo podem, ou devem, desempenhar num contexto de acção colectiva segundo uma lógica de planeamento participado, estratégico e em parceria.

Os princípios da governança exigem, justamente, que o planeamento seja participado, isto é, que seja realizado em parceria pelos actores que o vão colocar em prática, executando-o, na concretização dos objectivos e acções planeadas. Do mesmo modo que ele deverá permitir, também, a participação alargada dos actores directamente afectados por essas acções, enquanto decisores, técnicos ou população-alvo. Acresce que para ser efectivamente estratégico o planeamento terá de implicar convenientemente, desde o primeiro momento, a generalidade dos actores.

O que aqui pretendemos trazer, para reflexão e debate, resulta de uma experiência de trabalho de múltiplas e diversificadas participações ao nível do planeamento socioterritorial, respondendo ao apelo feito à sociologia e às ciências sociais, apelo esse baseado nos pressupostos e exigências acima mencionados. Trata-se de perspectivas e exigências de trabalho com as quais os agentes locais do desenvolvimento e da intervenção social (ou socioeconómica) se viram confrontados, mais ou menos repentinamente, e face às quais manifestaram, eles próprios, sérias dificuldades para com elas lidar. Acresce que as expectativas da prestação do trabalho que a este nível pode ser desenvolvido pela sociologia vão mais ao encontro da postura cientificamente legitimada pela comunidade científica e daquela com que os sociólogos mais habituados estão a lidar - a postura hipotético-dedutiva, baseada em instrumentos metodológicos razoavelmente testados e legitimados pela comunidade científica da sociologia. Contudo, essa é uma postura desajustada, no contexto do trabalho em planeamento estratégico e mesmo contraditória com os princípios requeridos pela noção de governança e planeamento estratégico participado, que acima enunciámos.

\section{Texto e contexto de uma reflexão}

O presente artigo procura dar conta de um conjunto de experiências concretas de trabalho em que aquelas questões se colocaram, em dois planos. Por um lado, no plano da postura da sociologia e do sociólogo face a um tal terreno de trabalho e a uma específica modalidade de exercício das suas competências profissionais e científicas. Por outro lado, no plano do concreto da realidade do país, com o seu nível de desenvolvimento próprio e a sua especificidade, em termos económicos, políticos, sociais e culturais, confrontado, sobretudo na última década, com a pressão para acelerar processos de desenvolvimento a todos aqueles níveis e, simultaneamente, fazer face às novas exigências da fase de transição que acima enunciámos sumariamente.

Não é possível discutir o primeiro plano sem antes debater o segundo, sendo imprescindível, no momento actual, em que os sociólogos são frequentemente chamados a intervir em instâncias de governança e planeamento, que se pretende estratégico, clarificar questões essenciais do ponto de vista do contexto social em que a prestação dos sociólogos é requerida, para depois clarificar questões, em parte decorrentes daquele contexto social, do ponto de vista metodológico e de deontologia da profissão, visando qualificar e regular a própria prestação da sociologia naquele terreno.

a) $\mathrm{O}$ contexto da reflexão: o país numa encruzilhada

No plano do concreto da realidade do contexto social em que um tal contributo da sociologia é requerido, importa referir que a especificidade do nível de desenvolvimento do país, e do seu percurso histórico, parece evidenciar que Portugal se encontra numa encruzilhada em que tem de lidar, simultaneamente, com os efeitos da transição de modelo societal e com as fragilidades do seu nível de desenvolvimento em termos económicos, sociais, políticos e culturais.

Por um lado tem de procurar desenvolver, ao nível local, instrumentos e procedimentos metodológicos de acção planeada para fazer face 
aos riscos, à complexidade e contradições de efeitos daquela transição, assim como para se procurar posicionar favoravelmente face aos potenciais desafios e oportunidades para o desenvolvimento local. Trata-se, em alguns casos de uma necessidade, e noutros da consciência de uma capacidade, para encetar fluxos e redes de natureza política, económica e cultural, que numa boa parte dos casos não passam pela mediação do governo central.

Por outro lado, o país confronta-se, ainda, com um défice de enraizamento de uma cultura de democraticidade e um défice de modernidade na gestão e administração (pública e privada), que constituem sérios obstáculos à adopção de princípios de governança e que não são ultrapassáveis em tempo curto.

A ideia de governança - ao implicar a descentralização de responsabilidades para os agentes locais, e para os municípios em primeiro lugar, participação cívica dos cidadãos e utilização das redes e parcerias para atingir objectivos comuns - veio tornar evidentes aquelas fragilidades do país.

(i) Défice de enraizamento de uma cultura de democraticidade

A noção de governança pressupõe a necessidade e capacidade de transparência na assunção de estratégias e interesses, possibilidade de questionar as práticas do poder hierarquicamente estabelecido, assunção de divergências, debate e discussão crítica das opções, perspectivas e decisões e uma avaliação permanente e rigorosa do trabalho desenvolvido.

Pressupõe, no fundo, uma cultura de parceria em regime horizontal e uma responsabilização partilhada da tomada de decisão, a sua submissão à discussão crítica e aberta e a prestação de contas (accountability) por parte dos órgãos da governação, como daqueles que têm acento nas instâncias de governança, que encontra sérias resistências na prática.

Por outro lado, a ideia de governança pressupõe, igualmente, a transparência da gestão de recursos e a sua utilização em prol do desenvolvimento sustentado, eficiente e equitativo do ponto de vista social. Entre outros factores, o peso determinante do sector fundiário e imobiliário no país, constitui-se num obstáculo que exige, por maioria de razão, uma gestão transparente da relação com os recursos e com os agentes aí implicados.

$\mathrm{O}$ sistema de financiamento do governo local revela-se, a este nível, como perverso, na medida em que é frequentemente responsável por um crescimento urbanístico a "todo o custo", com inevitáveis consequências para a coesão territorial, sustentabilidade e transparência na gestão ao nível local.

Um défice de uma cultura de planeamento que implica igualmente um défice de uma cultura de avaliação, sendo este resultado das insuficiências de modernidade na gestão e simultaneamente do défice de cultura de democraticidade, têm obstado às transformações exigidas pelos princípios de "boa governança", que poderão obviar o atraso estrutural que o país ainda regista.

(ii) Défice de modernidade na gestão e administração

Um dos paradoxos da ideia de governança é que ela pressupõe, igualmente, a inovação de procedimentos metodológicos na gestão, administração e planeamento da acção colectiva, quando os contextos porventura mais carentes de uma perspectiva de governança serão aqueles onde se regista um maior défice de modernidade àqueles níveis.

O que muitas experiências em curso no país demonstram, também, é uma grande fragilidade, particularmente evidente ao nível local, no que concerne a aspectos elementares das estruturas orgânicas das instituições, do governo central, do governo local, do "terceiro sector" ou da própria actividade empresarial.

Em primeiro lugar, há, àqueles níveis, uma carência forte de uma gestão moderna, democrática, eficaz e eficiente dos recursos locais, e fortes lacunas de formação técnica e formação cívica, para encetar procedimentos de planeamento da acção, como elaboração de projectos, avaliação rigorosa dos mesmos, construção de sistemas de comunicação e produção de informação capazes de agilizar e tornar mais eficazes as actividades desenvolvidas pelos diversos parceiros locais.

Em segundo lugar, há uma forte carência de capacidade de inovação de procedimentos e 
de modelos de intervenção social e, em muitos casos, uma resistência a essa mesma inovação, quer no tocante a metodologias de intervenção, quer no tocante a metodologias de planeamento e conhecimento da realidade local.

Em terceiro lugar, quando essa inovação existe, ela não é convenientemente divulgada no que deveria constituir uma prática corrente de marketing socioterritorial, tendo em conta a importância de disseminação das boas práticas e das experiências replicáveis, factor de motivação e de alavanca para a obtenção de melhores resultados ao nível do desenvolvimento local.

b) O texto da reflexão: a sociologia e o trabalho em planeamento

No plano da postura da sociologia e do sociólogo face a um tal terreno de exercício da profissão, o primeiro princípio de que devemos partir é o de que as instâncias de governança, e as suas parcerias, não constituem espaços isentos de iniquidade das respectivas estruturas de poder e de divergência de estratégias e de interesses. Pelo contrário, os diversos actores representados nessas parcerias (órgãos descentralizados do governo central, governo local, instituições não governamentais, do associativismo e do voluntariado, líderes locais, etc.) detêm estratégias diversas com prioridades diferentes e prosseguem interesses não necessariamente convergentes, possuindo graus de poder e capacidade de decisão igualmente diferenciados. Uma parceria não é um grupo de amigos, mas um lugar de negociação de projectos, estratégias, interesses, com base numa distribuição desigual, à partida, de recursos e meios de acção na posse de cada um dos parceiros.

Quando o sociólogo é chamado a intervir num contexto de parceria ele não pode esquecer a existência prévia do sistema de actores, do respectivo jogo, das lógicas de relação de poder e quadros de acção enraizados, onde pontuam os factores estruturais do contexto societal e as especificidades locais, em que a parceria se inscreve, incluindo todos os mecanismos de poder, respectiva desigualdade e factores de inclusão de uns e exclusão de outros.

Num tal terreno de exercício da profissão, o sociólogo tem de ter em conta, então, duas questões fundamentais, em particular. Ter, por um lado, a consciência de que quem encomenda e financia a sua participação é, sempre, um dos actores do sistema que vai analisar e no qual, e com o qual, vai trabalhar. $\mathrm{O}$ princípio de equidistância em relação aos diversos actores aplica-se, também necessariamente, portanto, em relação àquele actor. Ter, por outro lado, a consciência de que este tipo de intervenção da sociologia exige uma outra postura do sociólogo. "Não se procura verificar as hipóteses, desenvolvidas de forma genérica e fora do contexto, mas reconstruir do 'interior' a lógica e as propriedades de uma ordem local" (Guerra, 2000a:48). Assim sendo, "a prioridade é dada ao terreno e à estruturação de um campo de acção sempre contingente e particular; ao desenvolvimento de modelos descritivos e interpretativos que colam esse terreno às suas particularidades e contingências." (Guerra, 2000a:48). Torna-se imprescindível o recurso a uma postura indutiva de investigação-acção que possibilite, de facto, a participação dos actores na elaboração do diagnóstico e do plano de acção, na construção de um projecto de intervenção ou desenvolvimento.

(i) O jogo do lado da procura

Com muita frequência, quem encomenda e financia a participação do especialista das ciências sociais procura, com graus diversos, influenciar a seu favor e manipular os resultados daquela participação. O trabalho de planeamento possui três componentes fundamentais: diagnóstico, plano e monitorização/avaliação. No que concerne, em particular, ao diagnóstico, ele constitui-se como um elemento fundamental, também deste ponto de vista. Porque, necessariamente, tem de revelar dados do quadro de actores e do sistema de acção que, muitas vezes, não são favoráveis aos interesses, estratégias e práticas de uma parte dos actores e em particular àqueles que objectivamente detêm maiores responsabilidades no sistema, ou que subjectivamente chamam a si essas responsabilidades. Porque os resultados do diagnóstico determinam o sentido e direcção da acção, dos objectivos, medidas e projectos do Plano.

O maior ou menor grau do défice de cultura de democraticidade, de modernidade da gestão e administração, de uma cultura científica e de uma cultura de planeamento e de avaliação, de um determinado contexto territorial, determinam indele- 
velmente as expectativas e a postura face ao diagnóstico, nomeadamente por parte da entidade financiadora do mesmo. Entidade essa que, na maioria dos casos das instâncias de governança local, é o respectivo município e, em particular, o autarca que nele detém o poder de decisão.

O sociólogo deve contar, pois, com a expectativa, frequente por parte de quem encomendou o seu trabalho, que os resultados do diagnóstico vão ao encontro da estratégia e interesses do actor autor da "encomenda". Deve contar com a expectativa de que o diagnóstico não revele alguns elementos da realidade local, do ponto de vista dos problemas e necessidades diagnosticados, das causalidades desses problemas, das redes de relações entre actores, dos conflitos e divergências, dos interesses e estratégias em presença. Deve contar com o antagonismo activo dos actores que vêem nos resultados do diagnóstico a sua posição questionada e que interpretam esses resultados como não lhes sendo favoráveis.

Por outro lado, não devemos esquecer que o país se encontra, ainda, numa segunda geração do trabalho autárquico e com grande dificuldade para transitar para a terceira geração, devido aos défices acima referidos. Numa primeira geração tratou-se, na maioria do território nacional, da infra-estruturação básica: saneamento, electrificação, arruamentos, rede viária. Numa segunda geração, a edificação de equipamentos sociais, habitação social e arranjos paisagísticos. Numa terceira geração do trabalho autárquico haverá que privilegiar as dimensões imateriais, como o planeamento e as instâncias de governança em que os autarcas desempenham um papel de mediador, e empreendedor do desenvolvimento, com base na construção de projectos por parte das parcerias dos cidadãos organizados e das empresas locais. Trata-se de privilegiar, não a dimensão física (dos equipamentos, dos espaços), mas sim os "conteúdos" a conferir a esses equipamentos e espaços, uma aposta na "massa cinzenta" dos respectivos contextos territoriais.

Ora, enquanto a actual geração de autarcas não for reciclada, só excepcionalmente as expectativas em relação à prestação da sociologia, em contextos de governança e planeamento estratégico, poderão ser outras que não aquelas que depositaram no trabalho do "planeamento físico". Um tipo de planeamento que não discute estratégias, não desenha desafios e objectivos, não define parcerias privilegiadas para a prossecução dos objectivos, em função da maior ou menor mobilização dos actores face a cada um desses objectivos. Daí que, com frequência, os autarcas receiem o diagnóstico participado e estratégico, a sua natureza "excessivamente ambiciosa" quanto a metas e objectivos a atingir, que esperem que o diagnóstico lhes diga o que devem construir, e onde, e que, quando não vejam nos resultados obtidos a legitimação das suas práticas e estratégias, procurem questionar o carácter científico das metodologias de trabalho adoptadas.

Constitui, também, um factor de tensão no planeamento com recurso à análise estratégica, o facto da existência necessária de um programa prévio, traçado no programa eleitoral por parte do autarca eleito, ser interpretado como óbice à proposição de estratégias interpretadas como alternativas ou, por vezes, como antagónicas daquelas enunciadas em programa eleitoral. Ou, ainda, a incapacidade frequentemente demonstrada para o raciocínio estratégico e concepção racional de objectivos a atingir, preteridos em favor de lógicas meramente eleitorais ou de concorrência, ao invés de cooperação, com os municípios vizinhos. A não aplicação do princípio da subsidiariedade na implantação de equipamentos e serviços, será o melhor exemplo dessa concorrência sem lógica racional e dissonante dos princípios de racionalidade estratégica e acção planeada. As consequências são a ineficácia e ineficiência na utilização dos recursos ao nível local.

Em regra, o autor da encomenda, tudo fará, pois, para controlar politicamente a seu favor os resultados do diagnóstico. Não devemos, nunca, perder de vista que ele é um actor político e é nesse terreno que actua. Os restantes actores, em menor grau, também procuram, por vezes, influenciar os resultados do diagnóstico. Contudo, ao contrário dos municípios, não têm a seu favor o "trunfo" do financiamento do diagnóstico nem o ónus da responsabilidade política da governação local.

$\mathrm{Um}$ contexto de governança territorial de âmbito local é, sempre, um contexto em que o município tem de assumir um papel charneira, mas em que tal passa, também, pela perda, nesse contexto, da capacidade de decisão que existe, de forma quase exclusiva, num contexto de governação ao nível local. A governança implica, como antes 
se referiu, partilha de poder e de capacidade de decisão, mas não deveria deixar de implicar, do mesmo passo, responsabilização dos restantes parceiros, tanto do "terceiro sector" como - e isto é essencial -, dos órgãos desconcentrados do poder central e dos próprios agentes económicos privados locais.

(ii) O jogo do lado da oferta

O terreno da governança e do planeamento estratégico participado, com o contributo dos especialistas das ciências sociais faz, igualmente, apelo a uma postura inovadora e imaginativa por parte da própria sociologia. Em primeiro lugar por se tratar de um contexto em que se vai lidar com a presença de três lógicas e racionalidades fundamentais e distintas: a política, a técnica e a científica. $\mathrm{O}$ sociólogo inscreve-se neste terreno de exercício da profissão como um dos actores, embora desejavelmente equidistante em relação aos restantes actores. No entanto, o seu papel nunca é neutro, na medida em que poderá contribuir para a consolidação e reforço de estruturas desiguais de poder e justiça social, ou para a redução de desigualdades e injustiças sociais, consoante o sentido do seu desempenho na mediação das relações entre os restantes actores e na capacitação para a participação e implicação de todos eles, com particular preocupação de equidade na participação cívica e justiça social, no modo como procurará criar espaço para a inclusão dos que se encontram excluídos de uma cidadania activa e que, de acordo com os princípios da governança, deverão ser objecto de discriminação positiva.

A ausência de níveis razoáveis de uma cultura científica no país que se evidencia na não valorização do saber e do "saber-fazer", na não consciência, frequente, por parte dos agentes políticos, da existência de lógicas e racionalidades distintas entre a esfera política, a técnica e a científica, são alguns elementos responsáveis por expectativas erróneas do contributo das ciências sociais a este nível.

A natureza experimental de algumas metodologias de trabalho em planeamento estratégico participado, não é inteligível por uma boa parte dos actores e considera-se que o planeamento exige metodologias que se têm como infalíveis, numa perspectiva positivista da ciência, onde o inquéri- to sociológico, ou modelos matemáticos de planeamento, são tidos como "mais científicos" do que metodologias como fóruns comunitários e análise da estratégia de actores, frequentemente olhadas com desconfiança, fundamentalmente porque consagram, metodologicamente, os princípios da governança.

Sucede, também, que os próprios sociólogos, por vezes, contribuem para aquela visão ao tomarem o inquérito sociológico e a análise estatística como as metodologias privilegiadas de diagnóstico, quando elas são apenas dois instrumentos, entre outros, e nem sequer aqueles que se revelam mais ajustados à dimensão participativa do diagnóstico.

Ao especialista em planeamento cabe, com frequência, também, um papel pedagógico, no sentido de divulgar a diversidade de metodologias e as suas competências específicas, bem como - tarefa mais complexa -, dar conta da natureza aberta do debate científico em torno dos paradigmas possíveis e da complexa relação entre teoria e acção que na área do planeamento adquire lugar central (Guerra, 2000a e 2002). Esta é, porém, uma reflexão largamente por fazer mesmo no interior da comunidade científica.

Importa, por outro lado, não alimentar ilusões no que concerne à ideia de planeamento participado que, ao invés de desencadearem a mobilização dos actores para o exercício de uma cidadania activa e participação empenhada em instâncias de governança, através das respectivas parcerias, poderiam contribuir, definitivamente, para o descrédito de tais princípios e desmotivação dos agentes do desenvolvimento local.

A situação desejável é que aquela participação seja tão alargada quanto possível, mas ela será sempre parcial, por razões que se prendem com a estruturação do poder, a desigual distribuição dos recursos e a natureza especializada do conhecimento técnico-científico aplicado ao planeamento. A capacidade para avaliar com rigor as causalidades dos problemas sociais, interpretar dados, construir indicadores, exige competências técnico-científicas que a maioria dos actores não detém. Nem mesmo uma parte daqueles que exercem funções técnicas nos órgãos da administração central, ou local, e que deveriam desenvolver a sua acção com base naquelas competências. 
A maioria dos diagnósticos produzidos em contextos de governança, no âmbito do desenvolvimento local do país, evidenciam um dilema que importa ultrapassar. Ou, por um lado, o diagnóstico é "rigoroso e científico", mas não foi razoavelmente participado, portanto não é estratégico, não permitindo a sua apropriação, manuseamento e utilização operativa, por parte dos agentes do desenvolvimento local. Com frequência trata-se de "encomendas" feitas a centros de investigação, ou empresas especializadas, que realizaram o diagnóstico com base nas metodologias quantitativas acima referidas, sem integrar as dimensões estratégicas e os quadros de actores em presença e, obviamente, reduzindo a participação dos actores na produção do diagnóstico à sua audição em entrevistas individuais ou colectivas. $\mathrm{Ou}$, por outro lado, o diagnóstico é razoavelmente "participado", mas não é rigoroso nem científico, o que constitui o que poderíamos apelidar de "populismo científico". Portanto, não é, igualmente, estratégico, pois não resulta senão das "impressões", ou leituras subjectivas dos actores e é expressão acrítica da manipulação de resultados pelos agentes envolvidos no "jogo" do sistema assim diagnosticado. O recurso às técnicas de análise de dados é incipiente e falho de rigor científico e a reflexão estratégica e a análise de causalidades sobre os problemas identificados, estão ausentes.

Um diagnóstico que se quer estratégico exige capacidade de selecção da informação pertinente, concentração no essencial e não dispersão pelo acessório. Ponderação, realismo e pragmatismo na selecção conjugada do âmbito territorial do diagnóstico, das respectivas unidades de análise e de referência comparativa, com o grau de profundidade e extensão temática, em função, uma vez mais, da pertinência específica de cada unidade territorial, de cada tema, ou área problemática. Ainda é frequente confundir um diagnóstico social com uma "caracterização social", em que ao invés de se diagnosticarem os problemas, as necessidades e as estratégias existentes, ou alternativas, para a intervenção, num contexto específico em análise, se produz uma caracterização genérica da população, a partir de indicadores estereotipados e independentes da especificidade contextual de cada território preciso.

Realismo e pragmatismo, se são exigências do planeamento estratégico, por definição, deveri- am sê-lo também, por maioria de razão, quando estamos a falar de um contexto societal com as fragilidades que atrás identificámos.

Nesse sentido, tendo como preocupação alargar as possibilidades participativas dos actores, mobilizando-os e fomentando a sua implicação na construção de projectos de âmbito local, sem descurar o rigor técnico-científico, no que concerne em particular à fase inicial do projecto - o diagnóstico - julgamos que se deveriam concentrar esforços na capacidade imaginativa para diagnosticar "cada caso como um caso", sem perder de vista a necessidade de o referenciar comparativamente com outras unidades territoriais e, sobretudo, atender às escalas territoriais diversas em que o contexto em análise se integra. Deveria, igualmente, estabelecer-se um patamar mínimo de exigência em matéria de formação e auto-formação contínuas para a produção de diagnósticos que conseguissem, de forma participada, identificar e hierarquizar os problemas e necessidades fundamentais, a partir, por exemplo, da realização de fóruns comunitários, ou reuniões alargadas com os actores-chave e a população alvo da intervenção. De seguida, efectuar um esforço para distinguir problemas sociais e necessidades sociais. Tarefa complexa ao nível das parcerias de intervenção social e desenvolvimento local e que por isso mesmo exige a participação cientificamente informada da sociologia. Bem assim como o exercício subsequente de reflexão e análise das causalidades dos problemas. Procurar, depois, "consensualizar" as áreas problemáticas chave do contexto de intervenção, e sobre cada uma delas efectuar um exercício, em profundidade, de reflexão estratégica, identificando as respectivas potencialidades e fragilidades endógenas e as oportunidades e ameaças exógenas. Procurar, finalmente, construir um sistema de indicadores-chave essenciais e recolher e analisar a respectiva informação que permita avançar, de forma segura e sem simplismos de análise, para a fase seguinte, de construção do plano de acção. Para a construção do plano de acção seria fundamental, ainda, contar com uma análise das estratégias dos actores em presença, ou actores-chave do sistema diagnosticado. Uma vez mais se exige a intervenção especializada por parte de quem reúna as competências técnico-científicas necessárias para a aplicação daquela metodologia. 


\section{O conceito de governança como processo: notas para posterior aprofundamento da reflexão}

Em face do anteriormente exposto, a ideia de governança, por maioria de razão no caso português, deveria ser encarada como processo, tendo em conta não apenas o imperativo da criação de novos modos de regulação num contexto globalizado, como a necessidade de modernização e democraticidade da tomada de decisão ao nível das políticas sociais e urbanas locais, de um país onde algumas etapas estruturantes do desenvolvimento, e adquiridos da modernidade, estão ainda ausentes.

Enquanto processo, ela deve implicar a ideia de percurso de aprendizagem e nessa medida constitui-se num princípio normativo a atingir. Mas, por outro lado, nela se deve investir como veículo que evidencia um forte potencial para a ultrapassagem das lacunas de desenvolvimento e aproveitamento das oportunidades e desafios da globalização rumo a uma sociedade da informação e do conhecimento.

É nessa medida que se propõe uma noção pragmática do conceito de governança, não apenas para lidar com os efeitos da actual transição, como para ultrapassar as fragilidades do país no que concerne ao seu nível de desenvolvimento. Essa noção de governança implica um forte investimento no enraizamento de uma cultura de planeamento e actuação estratégica ao nível da acção colectiva e das políticas públicas locais para o desenvolvimento, apostadas na valorização das sinergias e racionalização dos recursos existentes. Implica, ainda, um forte investimento na formação para uma cidadania activa, sem a qual a própria noção de governança fica comprometida. Para uma tal noção do conceito de governança, alguns apontamentos para um aprofundamento da reflexão parecem decisivos:

(i) A acção planeada deve implicar uma visão sistémica e integrada do contexto territorial em causa, integrando de forma harmoniosa as dimensões económicas, sociais, ambientais e urbanísticas. Sendo já teoricamente um lugar comum, na prática de muitas experiências de parceria no terreno aquele pressuposto teórico continua ausente, apesar dos esforços continuados em sentido con- trário. Mobilizar competências técnicas interdisciplinares, e actores dos vários sectores pertinentes, para parcerias que protagonizem uma visão sistémica não é, ainda, tarefa fácil e aquelas dimensões continuam, em boa parte, de costas voltadas ao nível da sua acção quotidiana e das estratégias e objectivos que prosseguem.

(ii) Sendo conhecidas as insuficiências do país no que respeita ao exercício da cidadania, enquanto direitos e deveres dos cidadãos, por maioria de razão se manifestam profundas insuficiências, observáveis no terreno, no que concerne a uma cidadania activa (participação e implicação). Este é claramente um campo em que o investimento na formação e a disseminação de boas práticas podem trazer resultados positivos no processo de governança. Por outro lado há que instituir, como princípio das metodologias de intervenção e planeamento, o princípio do "participante ganhador". É também nesta medida que faz sentido uma noção pragmática da governança, no sentido em que a participação e implicação dos cidadãos e agentes locais deve pressupor a ideia de negociação e o carácter contratual presentes no planeamento estratégico. A co-responsabilização, a implicação e a consciência de que "ninguém ganha tudo mas todos ganham algo" com o exercício da governança. Há ainda que privilegiar a inovação no que concerne ao paradoxo de que os cidadãos e os contextos territoriais mais desprovidos de capacidades de poder que lhes permitam exercer a sua cidadania, são precisamente aqueles que devido a esse desprovimento de poder (recursos, competências, aptidões, saberes) menos presentes estão em contextos de decisão e exercício de uma cidadania activa. Uma vez mais se justifica a ideia de governança como processo, que neste caso deve caminhar no sentido de conferir, progressivamente, poder aos cidadãos e territórios excluídos, accionando, assim, uma política de inclusão e "empowerment" que, justamente, só pode ser concebida como processo. Uma redistribuição do poder é essencial para atingir um nível razoável de equilíbrio e coesão sociais. Finalmente, a mobilização e engajamento dos cidadãos para o exercício de uma cidadania activa, e prossecução da governança, encontra séria concorrência no crescimento endémico, no contexto actual, do que tem sido designado como "informalização" da econo- 
mia ("economias subterrâneas", "economias paralelas", "economias informais"). Sendo esta, por definição, uma manifestação oculta da exclusão social e dos factores de antítese à cidadania, é também, no actual contexto de lassidão dos mecanismos de regulação social, um dos sérios obstáculos à "boa governança”. A inovação técnica, científica e das experiências de intervenção terá, também, que passar pelas formas de lidar com aquela realidade endémica aos factores da transição societal contemporânea.

(iii) Tendo como base muito do que já foi referido a propósito das fragilidades do país, ao nível do seu desenvolvimento, mas também ao nível do défice de enraizamento de uma cultura de democraticidade, justifica-se pensar que as ciências sociais - nomeadamente as apetrechadas com instrumentos de trabalho em planeamento - têm um papel fundamental a desempenhar na prossecução dos processos de governança. Não apenas enquanto objecto de estudo, como também enquanto terreno de exercício de competências técnico-científicas em que ao especialista em planeamento compete desempenhar múltiplos papéis que passam pelo acompanhamento e mediação técnica e cientificamente informada das parcerias; pela avaliação da sua acção; pela formação dos parceiros, etc. Trata-se, fundamentalmente, de um trabalho em que progressivamente uns ganham em conhecimento científico da realidade de múltiplas e heterogéneas experiências locais. Enquanto outros ganham em instrumentos operativos para, de forma crescentemente mais eficaz, eficiente e socialmente mais inclusiva, levarem a bom porto o processo de governança, como novo modo de regulação e instrumento para lidar com os riscos e desafios da transição.

(iv) Uma nota breve, e a merecer reflexão mais aprofundada, sobre a participação dos agentes económicos privados (as empresas) no processo de governança. É também nossa convicção que a acção pública para o desenvolvimento local e os pro- cessos de governança não podem deixar de implicar, igualmente, os agentes económicos locais. A maioria dos programas e projectos de intervenção na esfera do "social" tem deixado de fora os agentes económicos privados. A economia social, o sector produtivo associativo e cooperativo têm, apesar de tudo, pontuado no exercício da governança local. No actual contexto de globalização e tendo em conta as consequências socioeconómicas do mesmo (riscos ambientais e sociais) e o decréscimo do Estado enquanto entidade reguladora em termos sociais -, o apelo à responsabilização social das empresas, apelo já efectuado pela Comissão Europeia, através do respectivo Livro Verde (CCE, 2001), é uma necessidade imperiosa para uma governança bem sucedida. O planeamento da intervenção social local que não mobilize e implique os agentes empresariais não pode ser tido como estratégico, do mesmo modo que as empresas não podem continuar a ter uma perspectiva externa face aos problemas sociais e ambientais e de mera reivindicação e crítica face ao Estado. Este é um exemplo em que as experiências conhecidas dão conta de como, apesar de tudo, os contextos territoriais de menor dimensão oferecem um potencial superior na superação deste obstáculo. Também aqui importaria disseminar os resultados destas práticas bem sucedidas.

(v) Finalmente, a governança local, encarada, também, como forma de responsabilização dos cidadãos e agentes locais e implicando a acção colectiva e tomada de decisão ao nível local, não pode, do mesmo passo, deixar de implicar a participação do Estado central na partilha de poder e responsabilidades com os restantes agentes públicos e privados. Considerando as fragilidades do nível de desenvolvimento do país, por maioria de razão, a passagem da responsabilidade da decisão política e da gestão e planeamento, da vida local, em exclusivo para os agentes públicos e privados locais, possuiria efeitos perversos para os processos de governança comprometendo, inclusive, os seus próprios princípios. 


\section{Referências Bibliográficas}

ALBROW, Martin, 1997, "Travelling beyond Local Cultures: Socioscapes in a Global City", in EADE, John, (org.), Living the Global City: Globalization as Local Process, London, Routledge, pp. 37-55.

AMIN, Ash, (1994), "Post-Fordism: Models, Fantasies and Phantoms of Transition" in AMIN, Ash (org.), Post-Fordism: a Reader, Oxford, Blackwell, pp. 1-39.

BUFFONY, Laura, 1997, "Rethinking Poverty in Globalized Conditions", in EADE, John, (org.), Living the Global City: Globalization as Local Process, London, Routledge, pp. 110-126.

COLLINGE, Chris, HALL, Stephen, 1997, "Hegemony and Regime in Urban Governance: Towards a Theory of The Locally Networked States", in JEWSON, Nick, MACGREGOR, Susanne (orgs.), Transforming Cities: Contested Governance and New Spatial Divisions, London, Routledge, pp. 129-152.

CCE, 2001, "Promover um Quadro Europeu para a Responsabilidade Social das Empresas", Livro Verde, Bruxelas, 18-07-2001, COM (2001) 366 final.

CCE, 2003, "Governança e Desenvolvimento", Bruxelas, 20-10-2003, COM (2003) 615 final.

EUROCITIES, 2004, "Déclaration de Vienne - version finale: vers une approche intégrée des questions urbaines et une coopération renforcée au sein de l'Union Européenne", Vienne, Autriche, le 12 novembre 2004.

ESSER, Joseph, HIRSCH, Joachim, 1994, "The Crisis of Fordism and the Dimensions of a 'Post-Fordist' Regional and Urban Structure" in AMIN, Ash (org.), Post-Fordism: a Reader, Oxford, Blackwell, pp. 71-97.

GEDDES, Mike, 1997, "Poverty, Excluded Communities and Local Democracy", in JEWSON, Nick, MACGREGOR, Susanne (orgs.), Transforming Cities: Contested Governance and New Spatial Divisions, London, Routledge, pp. 205-218.

GUERRA, Isabel, 2000a, Fundamentos e Processos de ume Sociologia de Acção, o Planeamento em Ciências Sociais, Cascais, Principia.

GUERRA, Isabel, 2000b, "Planeamento Estratégico das Cidades: Organização do Espaço e Acção Colectiva", Cidades - Comunidades e Territórios, n. ${ }^{\circ} 1$, Lisboa, CET/ISCTE, pp. 37-55.
GUERRA, Isabel, 2002, "Cidadania, exclusões e solidariedades. Paradoxos e sentidos das "novas políticas sociais", Revista Crítica de Ciências Sociais, n. ${ }^{\circ}$ 63, Coimbra, CES, pp. 47-74.

JESSOP, Bob, 1997, “The entrepreneurial city: Re-imaging Localities, Redesigning Economic Governance, or Restructuring Capital?", in JEWSON, Nick, MACGREGOR, Susanne (orgs.), Transforming Cities: Contested Governance and New Spatial Divisions, London, Routledge, pp. 28-41.

JEWSON, Nick; MACGREGOR, Susanne, 1997, “Transforming Cities: Social Exclusion and The Reinvention of Partnership", in JEWSON, Nick; MACGREGOR, Susanne (orgs.), Transforming Cities: Contested Governance and New Spatial Divisions, London, Routledge, pp. 1-15.

LOPES, Raul, 2003, Competitividade, Inovação e Territórios, Oeiras, Celta Editora.

MAYER, Margit, 1994, "Post-Fordism City Politics", in AMIN, Ash (org.), Post-Fordism: a Reader, Oxford, Blackwell, pp. 316-337.

PERESTRELO, Margarida, 2002, "Planeamento Estratégico e Avaliação: Metodologias de Análise Prospectiva”, Cidades - Comunidades e Territórios, n. ${ }^{\circ} 4$, Lisboa, CET/ISCTE, pp. $33-43$

RODRIGUES, Walter, (coord.), ALMEIDA, Lisete, BANDEIRA, Graça, LUVUMBA, Felícia, PACHECO, Susana, MARQUES COUTO, Óscar; PERESTRELO, Margarida, SANTOS, Eduardo Jorge dos, 1998, Diagnóstico Avaliativo da Situação Sócio-Urbanística nas Freguesias de Miragaia e Vitória - Porto, Relatório Final, CET/ISCTE.

RODRIGUES, Walter, (coord.), PERESTRELO, Margarida; MOURA, Dulce; AMOR, Teresa, 2002, Estudo de Diagnóstico Social do Concelho de Almada, Relatório Final, CET/ISCTE.

RODRIGUES, Walter (coord.); MOURA, Dulce, 2003, Estratégias para a Juventude no Desenvolvimento Sócio-Económico de Mortágua: Documento para a Acção, Relatório Final, CET/ISCTE.

RODRIGUES, Walter (coord.), AMOR, Teresa, 2005, Diagnóstico Social do Concelho de Sesimbra, Relatório Final, CET/ /ISCTE.

UNCHS, 2000, "UNCHS (Habitat) - The Global Campaign for Good Urban Governance", Environment \& Urbanization, Vol. 12, n. ${ }^{\circ}$ 1, pp. 197-202 